\title{
Effects and efficacy of laparoscopic fundoplication in children with GERD: a prospective, multicenter study
}

\author{
Femke A. Mauritz ${ }^{1,3}$ (D) J. M. Conchillo ${ }^{4}$ - L. W. E. van Heurn ${ }^{5}$. \\ P. D. Siersema ${ }^{3}$ C. E. J. Sloots ${ }^{6}$ R. H. J. Houwen ${ }^{2}$ D. C. van der Zee ${ }^{1}$. \\ M. Y. A. van Herwaarden-Lindeboom ${ }^{1}$
}

Received: 30 March 2016/Accepted: 21 June 2016/Published online: 1 July 2016

(c) The Author(s) 2016. This article is published with open access at Springerlink.com

\begin{abstract}
Introduction Laparoscopic antireflux surgery (LARS) in children primarily aims to decrease reflux events and reduce reflux symptoms in children with therapy-resistant gastroesophageal reflux disease (GERD). The aim was to objectively assess the effect and efficacy of LARS in pediatric GERD patients and to identify parameters associated with failure of LARS.

Methods Twenty-five children with GERD [12 males, median age 6 (2-18) years] were included prospectively. Reflux-specific questionnaires, stationary manometry, 24-h multichannel intraluminal impedance $\mathrm{pH}$ monitoring (MII$\mathrm{pH}$ monitoring) and a ${ }^{13} \mathrm{C}$-labeled Na-octanoate breath test were used for clinical assessment before and 3 months after LARS.

Results After LARS, three of 25 patients had persisting/ recurrent reflux symptoms (one also had persistent
\end{abstract}

Femke A. Mauritz

femkemauritz@gmail.com

1 Department of Pediatric Surgery, Wilhelmina Children's Hospital, University Medical Center Utrecht, Room: KE.04.140.5, PO Box 85090, 3508 AB Utrecht, The Netherlands

2 Department of Pediatric Gastroenterology, Wilhelmina Children's Hospital, University Medical Center Utrecht, Utrecht, The Netherlands

3 Department of Gastroenterology and Hepatology, University Medical Center Utrecht, Utrecht, The Netherlands

4 Department of Gastroenterology and Hepatology, Maastricht University Medical Center, Maastricht, The Netherlands

5 Department of Pediatric Surgery, Emma Children's Hospital, Amsterdam Medical Center, Amsterdam, The Netherlands

6 Department of Pediatric Surgery, Erasmus MC - Sophia Children's Hospital, Rotterdam, The Netherlands pathological acid exposure on MII-pH monitoring). Newonset dysphagia was present in three patients after LARS. Total acid exposure time (AET) $(8.5-0.8 \% ; p<0.0001)$ and total number of reflux episodes $(p<0.001)$ significantly decreased and lower esophageal sphincter (LES) resting pressure significantly increased $(10-24 \mathrm{mmHg}$, $p<0.0001)$ after LARS. LES relaxation, peristaltic contractions and gastric emptying time did not change. The total number of reflux episodes on MII-pH monitoring before LARS was a significant predictor for the effect of the procedure on reflux reduction $(p<0.0001)$.

Conclusions In children with therapy-resistant GERD, LARS significantly reduces reflux symptoms, total acid exposure time (AET) and number of acidic as well as weakly acidic reflux episodes. LES resting pressure increases after LARS, but esophageal function and gastric emptying are not affected. LARS showed better reflux reduction in children with a higher number of reflux episodes on preoperative MII-pH monitoring.

Keywords Pediatric · Children · Reflux - GERD . Fundoplication · Efficacy

Gastroesophageal reflux disease (GERD) frequently occurs in the pediatric population [1,2]. In severe GERD resistant to medical treatment, laparoscopic antireflux surgery (LARS) can be warranted [2-4]. Many studies have been published on pediatric LARS [5-12]. Most of these studies had a retrospective design and could only conclude that the procedure resulted in symptom control in $57-100 \%$ of patients $[11,13,14]$. To assess the efficacy of LARS, it is important to use validated questionnaires before and after LARS. Such questionnaires, however, have not been used in the majority of pediatric LARS studies [15]. In addition to evaluation of 
reflux symptoms, more objective assessments of (acid) reflux, such as multichannel intraluminal impedance $\mathrm{pH}$ (MII-pH) monitoring, should be performed [9, 10, 16].

In previous published pediatric studies, objective assessments were primarily performed using only $\mathrm{pH}$ monitoring $[6,9,10,12]$. MII-pH monitoring enables quantification of both acid and weakly acidic reflux and the proximal extent of the refluxate [17] and therefore increases the yield of symptom association assessments in children [18]. Studies in children using MII in addition to $\mathrm{pH}$ monitoring so far either were retrospective [19] or only investigated efficacy in a selected patient population [20]. However, up to now none of the studies quantifying both reflux symptoms and more objective assessments of GERD after LARS have shown a correlation between both measurements $[9,10]$. It is therefore important to evaluate effects and efficacy of LARS using both validated questionnaires and objective assessment tools.

The success of LARS is determined by the disappearance or reduction of GERD, but is also influenced by postoperative sequelae, such as severe dysphagia and gas/bloating [21]. It is therefore indicated to identify predictors for failure in order to enable optimal preoperative counseling on the risk of persisting or recurrent GERD after LARS. Rosen et al. [19] addressed this issue in a retrospective study by trying to identify predictors for failure of LARS in children using preoperative MII-pH monitoring in 37 patients. However, no predictors could be identified in this study.

The aim of the current prospective study was to objectively assess the effect and efficacy of LARS in pediatric patients and to identify predictors of LARS failure.

\section{Methods}

We performed a prospective multicenter study in three University Medical Centers in the Netherlands that are specialized in performing laparoscopic fundoplication in children (Wilhelmina Children's Hospital, University Medical Center Utrecht (UMCU); Sophia's Children's Hospital, Erasmus University Medical Center (Erasmus MC) and Maastricht University Medical Center (MUMC). From July 2011 to December 2013 we prospectively included all pediatric patients diagnosed with PPI therapyresistant GERD. Patients who underwent any previous esophageal or gastric surgery (except previous gastrostomy placement) and those with structural abnormalities other than an esophageal hiatal hernia were excluded.

\section{Surgical procedures}

All laparoscopic fundoplication procedures were performed by experienced pediatric surgeons. In the UMCU
Utrecht, the anterior, partial fundoplication according to Thal [22] was used to perform fundoplication. In the other two UMCs (EMC and MUMC), the posterior, total fundoplication according to Nissen [23] was performed. Before fundoplication, the distal esophagus was fully mobilized; the distal $3 \mathrm{~cm}$ of the esophagus was repositioned back into the abdomen. Both vagal nerves were identified, and a crusplasty was performed routinely (UMCU and EMC). Thereafter, the fundoplication was constructed. The Thal fundoplication was performed by plicating the fundus of the stomach over $270^{\circ}$ against the distal anterior intra-abdominal part of the esophagus and the diaphragmatic crus $[9,22]$. A floppy Nissen was constructed with one of the sutures of the 360 degrees posterior wrap incorporated in the esophageal wall [23].

\section{Clinical assessment}

Before and 3 months after laparoscopic fundoplication, clinical assessment was performed using stationary manometry, 24-h multichannel intraluminal impedance $\mathrm{pH}$ monitoring (MII-pH monitoring), ${ }^{13} \mathrm{C}$-labeled Na-octanoate breath test and a reflux-specific symptom questionnaire. Surgical reinterventions, type and indication for reintervention, endoscopic procedures, use of antireflux medication, complications and comorbidities were registered in a prospective database.

\section{Reflux-specific symptom questionnaires}

To assess reflux symptoms, patients and/or their parents were asked to fill out the validated age-adjusted Gastroesophageal Reflux Symptom Questionnaire (GSQ) before and after LARS [24]. Reflux symptoms and dysphagia were scored for frequency and severity on a score ranging from 1 (none) to 7 (most severe). Symptoms were defined as no symptoms (no symptoms reported); mild (mild symptoms weekly); moderate (mild symptoms daily or severe symptoms weekly) and severe (severe symptoms daily). Reflux symptoms were scored using the symptoms heartburn, regurgitation, food refusal and vomiting. Furthermore, the need for acid suppressive therapy after LARS was registered.

\section{Nutritional status}

Weight and height measurements were converted to weight-for-length and length-for-age $z$ scores based on the Netherlands Organization for Applied Scientific Research (TNO) growth standards [25]. $Z$ scores allow comparison of an individual's weight or height, adjusting for age and sex relative to a reference population, expressed in standard deviations from the reference mean. 


\section{Stationary manometry}

For esophageal stationary manometry, age-adjusted stationary water-perfused sleeve-manometry catheters were used (Mui Scientific, Mississauga, Ontario, Canada). The sleeve-manometry catheter was positioned with the sleeve at the level of the lower esophageal sphincter (LES) using the pull-through technique. In a semi-recumbent position, patients received 10 liquid bolus challenges using saline combined with lemonade $(5 \mathrm{ml})$ in order to study the manometric response. During the study, data were recorded on the Stationary Solar Gastro System (Medical Measurement Systems, Enschede, The Netherlands). Manometry tracings were analyzed for LES resting and nadir pressure, LES relaxations, number of peristaltic contractions and peak amplitude of the contractions according to previously accepted standards [26].

\section{Ambulatory 24-h MII-pH monitoring}

Ambulatory 24-h MII-pH testing was conducted after cessation of all medication that may have an effect on gastrointestinal motility and acid secretion for at least 3 days. MII-pH monitoring was performed using an ageadjusted combined impedance $\mathrm{pH}$ catheter with six impedance segments and one ISFET $\mathrm{pH}$ electrode (Unisensor AG, Attikon, Switzerland). The $\mathrm{pH}$ electrode was positioned above the upper border of the manometrically localized lower esophageal sphincter. Impedance and $\mathrm{pH}$ signals were stored on a digital data logger (Ohmega, Medical Measurement Systems, Enschede, The Netherlands), using a sampling frequency of $50 \mathrm{~Hz}$. Patients were instructed to record reflux symptoms, supine resting periods and meals, including drinks, in a diary and by marking the symptom using the recording button on the data logger. The 24-h MII-pH tracings were analyzed for the number and acidity of reflux episodes according to previously described definitions [17]. Pathological acid exposure was defined as total acid exposure time (AET) $\geq 6 \%, \geq 9 \%$ in upright and $\geq 3 \%$ in the supine body position [27, 28]. The symptom index (SI) and the symptom association probability (SAP) were calculated if patients had experienced symptoms during the measurement [29, 30].

\section{Gastric emptying breath test}

To assess gastric emptying (GE) half-time, we used a ${ }^{13} \mathrm{C}$ labeled Na-octanoate breath test [31]. Subjects fasted for at least $6 \mathrm{~h}$ before the study. In children $>4$ years of age, a solid test meal containing ${ }^{13} \mathrm{C}$-labeled Na-octanoate was performed with $375-\mathrm{g}$ pancake containing $45 \mathrm{mg}$ of ${ }^{13} \mathrm{C}$ labeled Na-octanoate (a stable isotope).
For younger children or children who were unable to eat the pancake within $15 \mathrm{~min}, 100 \mathrm{mg}$ of ${ }^{13} \mathrm{C}$-labeled $\mathrm{Na}$ octanoate was added to a liquid formula (infant formula, full cream milk or chocolate milk). Breath samples were obtained in duplicate at 15-min intervals during the course of $4 \mathrm{~h}$ (for the liquid test, breath samples were obtained at 5 -min intervals during the first $30 \mathrm{~min}$ ). Hereafter, the ratio between ${ }^{12} \mathrm{CO}_{2}$ and ${ }^{13} \mathrm{CO}_{2}$ content in breath samples was analyzed with an isotope ratio mass spectrometer. Finally, three parameters were calculated. Gastric half-emptying time $\left(\mathrm{GGE}^{\mathrm{T}}{ }^{1} / 2\right)$ was defined as the time when the first half of the ${ }^{13} \mathrm{C}$-labeled substrate had been metabolized, that is, when the cumulative excretion of ${ }^{13} \mathrm{C}$ in the breath was half the ingested amount. Gastric emptying percentiles $(P)$ were calculated according to the reference values obtained by van den Driessche et al. [32]. GE percentiles higher than 75 were considered delayed and above 95 severely delayed. The gastric emptying coefficient (GEC) reflects a global index for GE, influenced by both the rate of appearance and disappearance of ${ }^{13} \mathrm{C}$ in breath.

\section{Sample size calculation}

A sample size of 50 patients was calculated based on the assumption that approximately $20 \%$ of pediatric GERD patients will fail after LARS. Success of LARS was defined as: (1) complete symptom relief and normalized MII-pH monitoring or (2) complete symptom relief and near-normal MII-pH monitoring or (3) normalized MII-pH monitoring combined with a significant improvement of reflux symptoms (complaints less than moderate/weekly). Using the logistic regression model according to Frank Harrell [33], five failures were required to reliably identify a determinant of failure. Determinant of interest was gastric emptying and age at time of operation.

\section{Patients}

In total 25 children were included in our study. After enrollment of the 25th patient, the study was stopped prematurely, because the inclusion rate was lower than anticipated. Mean age of the included patients was 6 (range 2-18) years at the time of fundoplication (Table 1). Five children $(80 \%)$ had normal neurodevelopment (NN), while impaired neurodevelopment (NI) was seen in five children $(20 \%)$. Cause of NI is shown in Table 2.

\section{Ethical approval and trial registration}

This study was registered at the start of the study in the Dutch national trial registry (www.trialregister.nl; Identifier: 2934). Ethical approval for this prospective multicenter study was obtained from the University Medical 
Table 1 Baseline characteristics

\begin{tabular}{lc}
\hline & (Median; IQR) \\
\hline Age at time of operation (years) & $6.0(3.0-11.0)$ \\
Duration of hospital admission (days) & $3.0(2.0-4.5)$ \\
\hline & $n(\%)$ \\
\hline Male gender & $12(48.0 \%)$ \\
Impaired neurodevelopment & $5(20.0 \%)$ \\
Gastrostomy preoperatively in situ & $4(16.0 \%)$
\end{tabular}

Table 2 Impaired neurodevelopment $(n=5)$

CHARGE syndrome

Mitochondrial complex II deficiency

Posthypoxic encephalopathy

Congenital rubella infection

Impaired neurodevelopment of unknown origin with autistic behavior

Center Utrecht Ethics Committee, and local approval was obtained by the remaining two participating centers. Prior to study procedures, informed consent from the patients' parents and children ( $\geq 12$ years) was obtained.

\section{Statistical analysis}

Continuous variables, when symmetric, were expressed as mean \pm standard error. Skewed variables were expressed as median with interquartile ranges (IQR). For statistical analysis, we used the paired sample $t$ test or the Wilcoxon signed-rank test, whenever appropriate. The McNemarBowker test was used to compare groups in case of nominal outcome measures. Exploratory subgroup analysis for all outcome measures was performed comparing neurodevelopment and type of fundoplication. The primary aim was to perform a logistic regression analysis if sufficient LARS failures were identified. Linear regression analysis was performed to identify determinants influencing the effect of LARS on reflux control measured by 24-h MII-pH monitoring. Determinant of interest was age at time of operation, neurodevelopment, type of fundoplication, preoperative number of reflux episodes on 24-h MII-pH monitoring and preoperative gastric emptying rate. Differences with a $p<0.05$ were considered statistically significant. All analyses were performed using IBM $^{\circledR}$ 22.0.0 SPSS statistical package (IBM, Armonk, NY).

\section{Results}

In total 18 Thal and 7 Nissen fundoplications were performed (Fig. 1). In all patients, fundoplication could be completed by laparoscopy. Perioperative complications were not observed. Median hospital admission time was 3.0 (2.0-4.5) days (Table 1). In one patient with retching based on impaired neurodevelopment a redo-fundoplication was indicated because of severe recurrent reflux (pathological reflux on 24-h pH monitoring and severe reflux symptoms) caused by hiatal herniation. Another patient required emergency gastroscopy to remove a food bolus impacted in the esophagus 1 day after LARS. In six children temporary nasogastric tube feeding was required to obtain sufficient caloric intake. Insufficient caloric intake was caused by transient dysphagia $(n=4)$, persistent dysphagia $(n=1)$ or rejection of oral feedings without dysphagia $(n=1)$.

\section{Symptom assessment}

All patients and/or parents completed the reflux-specific symptom questionnaire (Fig. 1). Overall reflux symptoms significantly decreased after LARS $(p=0.001)$. In three of $25(12 \%)$ patients, reflux symptoms persisted (1/3 also had persistent pathological acid exposure on MII-pH monitoring) (Table 3). The use of acid suppressive medication decreased from $100 \%$ of all patients preoperatively to $16 \%(n=4)$ after operation. Analysis in subgroups comparing children with $\mathrm{NI}$ to $\mathrm{NN}$ [NN (5\%) vs $\mathrm{NI}$ (40\%); $p=0.099$ ] and Nissen compared to Thal fundoplication [Nissen $(11 \%)$ vs Thal $(17 \%) ; p=0.597$ ] did not show significant differences in the presence of GERD symptoms after LARS.

Moderate-to-severe dysphagia was reported in eight (32\%) patients before LARS and in seven (28\%) patients 3 months after LARS ( $p=0.887$ ) (Table 3$)$. New-onset dysphagia was seen in three of these seven patients with dysphagia after LARS. Dysphagia more frequently occurred in NI children [NI (80\%) vs NN (15\%); $p=0.012$ ] after LARS compared to NN patients. Furthermore, there was a trend showing that children undergoing Nissen fundoplication had more frequently dysphagia compared to those undergoing Thal fundoplication [Nissen (57\%) vs Thal $(17 \%) ; p=0.066]$.

\section{Nutritional status}

Height-for-weight $[-0.2 \mathrm{SD}(-1.0$ to 0.7$)$ to $-0.5 \mathrm{SD}$ $(-1.3$ to 0.1$) ; p=0.57]$ and height-for-age [-0.9 SD $(-1.2$ to 0.1$)$ to $-1.0 \mathrm{SD}(-1.5$ to 0.4$) ; p=0.42$ ] scores remained similar when comparing preoperative to 3-month postoperative measurements. 
Fig. 1 Flowchart of patient selection and enrollment

\begin{tabular}{|c|c|}
\hline $\begin{array}{l}\text { Enrolled children with } \\
\text { therapy-resistant GERD } \\
\qquad(\mathrm{n}=25)\end{array}$ & \multirow{5}{*}{$\begin{array}{l}\text { Patients }(n=82) \text { excluded based on: } \\
\text { UMC Utrecht: } \\
\text {-Redo-fundoplication }(n=10) \\
\text {-Esophageal atresia }(n=8) \\
\text {-Achalasia }(n=2) \\
\text {-Corrosive burns of the esophagus and stomach } \\
(n=1) \\
\text {-Age }(<2)(n=1) \\
\text {-Parental refusal }(n=1)\end{array}$} \\
\hline & \\
\hline & \\
\hline & \\
\hline & \\
\hline Laparoscopic Thal fundoplication & Erasm us MC: \\
\hline$(n=18)$ & -Redo-fundoplication $(\mathrm{n}=2)$ \\
\hline and & -Esophageal atresia $(n=7)$ \\
\hline Laparoscopic Nissen fundoplication & - Tracheal stenosis/laryngeal cleft $(n=3)$ \\
\hline$(n=7)$ & $\begin{array}{l}\text {-Duodenal atresia }(n=2) \\
\text {-ICU/pressure support }(n=4)\end{array}$ \\
\hline & -Parental refusal $(\mathrm{n}=8)$ \\
\hline & Maastricht UMC: \\
\hline & -Redo-fundoplication $(n=4)$ \\
\hline $\begin{array}{l}\text { Postoperative Measurements } \\
\qquad(\mathrm{n}=25)\end{array}$ & $\begin{array}{l}\text {-Esophageal atresia }(n=4) \\
\text {-Pyloromyotomy for pyloric stenosis }(n=1) \\
\text {-Diaphragmatic paralysis }(n=1)\end{array}$ \\
\hline -Questionnaires $(\mathrm{n}=25)$ & -Age $(<2)(n=6)$ \\
\hline -Manometry/pH-impedance/ & $\begin{array}{l}\text {-ICU/pressure support }(n=2) \\
\text {-No written consent could be obtained }(n=1)\end{array}$ \\
\hline Gastric emptying breath test $(n=23)$ & -Parental refusal $(n=14)$ \\
\hline
\end{tabular}

Table 3 Symptom assessment

\begin{tabular}{lccc}
\hline & Preoperative $(n, \%)$ & $3-4$ months postoperative $(n, \%)$ & $p$ value \\
\hline Reflux symptoms & & & \\
None & $0(0 \%)$ & $17(68 \%)$ & 0.001 \\
Mild & $2(8 \%)$ & $5(20 \%)$ & \\
Moderate & $7(28 \%)$ & $2(8 \%)$ & 0.887 \\
Severe & $16(64 \%)$ & $1(4 \%)$ & \\
Dysphagia & & & \\
None & $13(52 \%)$ & $3(12 \%)$ & \\
Mild & $4(16 \%)$ & $3(12 \%)$ & \\
Moderate & $3(12 \%)$ & $4(16 \%)$ & \\
Severe & $5(20 \%)$ &
\end{tabular}

$n$ number of patients, $\%$ percentage of patients, $p<0.05$ is considered significant

\section{Clinical assessment tests}

Postoperative manometry, 24-h MII-pH monitoring and gastric emptying breath test were not performed in two patients because of parental refusal (Fig. 1). LES resting pressure significantly increased after fundoplication from $10 \mathrm{mmHg}$ (7-18) to $24 \mathrm{mmHg}(17-26), p<0.0001$. Nadir LES pressure also significantly increased from $0 \mathrm{mmHg}$ $(0-8)$ to $3.5 \mathrm{mmHg}(0-8)$ after LARS, $p<0.0001$. Complete LES relaxation, percentage of continued peristaltic contractions and peak amplitude all remained similar (Table 4). Subgroup analysis showed no differences comparing NI to NN children. Children undergoing Thal fundoplication had a significantly higher preoperative LES resting pressure compared to those who underwent Nissen fundoplication [Thal $(14.6 \mathrm{mmHg})$ vs Nissen $(6.5 \mathrm{mmHg})$; $p=0.001]$; however, after LARS no statistical difference was found [Thal $(22.7 \mathrm{mmHg})$ vs Nissen $(19.8 \mathrm{mmHg})$; $p=0.525]$. All other manometry outcome measures were similar when comparing Thal to Nissen fundoplication.

Twenty-four hour MII-pH monitoring showed a significant decrease in total acid exposure time and number of reflux episodes $(p<0.001$; Table 4$)$. Acidic, weakly acidic, liquid and mixed reflux episodes also decreased significantly (Table 4). In two patients pathological reflux persisted after LARS, although in one of these patients 
Table 4 Results of clinical assessment tests

\begin{tabular}{|c|c|c|c|}
\hline & Preoperative (IQR) & 3-4 months postoperative (IQR) & $p$ value \\
\hline \multicolumn{4}{|l|}{ 24-h MII-pH measurement } \\
\hline Total GER episodes & $91.5(8-230)$ & $14(2-153)$ & $<0.0001$ \\
\hline Acid GER episodes & $61.5(34.3-93.8)$ & $8(1-13)$ & $<0.0001$ \\
\hline Weakly acid GER episodes & $23(10.5-42)$ & $5(3-11)$ & 0.002 \\
\hline Liquid GER episodes & $55.5(11-153)$ & $10(2-96)$ & $<0.0001$ \\
\hline Mixed GER episodes & $37.5(3-176)$ & $3(0-57)$ & $<0.0001$ \\
\hline \multicolumn{4}{|l|}{ Proximal extend } \\
\hline Z1 (proximal esophagus) & $26.5(14.5-55.3)$ & $2(0-8)$ & $<0.001$ \\
\hline Z3 (mid esophagus) & $75.5(64.8-88)$ & $57(44-71)$ & 0.009 \\
\hline Z5 (distal esophagus) & $100(100-100)$ & $100(100-100)$ & NA \\
\hline Total acid exposure (\%) & $8.5(2.5-32.8)$ & $0.8(0-2.8)$ & $<0.0001$ \\
\hline Longest reflux episode (min) & $20.7(3.4-66.7)$ & $3.8(0-21.6)$ & $<0.0001$ \\
\hline SI $(\%)$ & $75(18.8-100)$ & $50(0-100)$ & 0.111 \\
\hline SAP $(\%)$ & $100(97.3-100)$ & $93.2(22.1-98.7)$ & 0.048 \\
\hline \multicolumn{4}{|l|}{ Stationary manometry } \\
\hline LES resting pressure $(\mathrm{mmHg})$ & $10(6.5-18)$ & $23.5(17-26)$ & $<0.0001$ \\
\hline LES nadir pressure $(\mathrm{mmHg})$ & $0(0-8)$ & $3.5(0-8)$ & $<0.0001$ \\
\hline Complete LES relaxation (\%) & $100(100-100)$ & $100(100-100)$ & 0.311 \\
\hline Continued peristaltic contraction (\%) & $100(100-100)$ & $100(100-100)$ & 0.149 \\
\hline Peak amplitude (mmHg) & $74(39-109)$ & $66(24-139)$ & 0.299 \\
\hline \multicolumn{4}{|l|}{ Gastric emptying test } \\
\hline Gastric emptying half-time (min) & $76.5(49.3-89)$ & $56(47-78)$ & 0.102 \\
\hline Gastric emptying percentile & $75(0-99)$ & $70(2-99)$ & 0.530 \\
\hline GEC & $3.0(2.5-5.6)$ & $3.6(2.3-4.7)$ & 0.463 \\
\hline
\end{tabular}

GER gastroesophageal reflux, $S I$ symptom index, SAP symptom association probability, NA not applicable, LES lower esophageal sphincter, $G E C$ gastric emptying coefficient, $I Q R$ interquartile range, $p<0.05$ is considerd significant

total acid exposure time (AET) decreased from $32.8 \%$ (severe pathological) to $9.7 \%$ (near-normal). Subgroup analysis comparing NI to NN children revealed that preoperative acid exposure time and total number of reflux episodes (RE) before LARS were significantly higher in NI children [AET: NN $(9.5 \%)$ vs NI $(19.3 \%) ; p=0.006$ and RE: NN (91.5) vs NI (181.4); $p=0.002]$. After LARS NI children still had more reflux, although it was not statistically significant [AET: NN (1.2\%) vs NI (7.2\%); $p=0.22$ and RE: NN (16.6) vs NI (41.8); $p=0.42]$. Other 24-h MII-pH outcome measures were similar comparing NI to NN children. Comparing Thal to Nissen fundoplication only identified a significant difference in preoperative total number of reflux episodes on 24-h MII-pH monitoring [AET: Thal (121.4) vs Nissen (76.7); $p=0.03$ ]; however, after LARS outcomes were not significantly different [AET: Thal (25.9) vs Nissen (11.4); $p=0.33)$.

GE half-time [77 $\mathrm{min}(0-113)$ to $56 \mathrm{~min}$ (14-103); $p=0.102]$ and GE percentiles did not significantly change after LARS (Table 4). However, looking at a subset of patients with preoperative delayed $(n=13)$ or severely delayed $(n=8) \mathrm{GE}, \mathrm{GE}$ half-time [84 $\mathrm{min}(58-106)$ to
$54.4 \min (40.3-87.3) ; p=0.023]$ and GE percentiles [85 (75-95) to 75 (10-85); $p=0.029]$ improved significantly. Furthermore, in four patients GE normalized after LARS (Fig. 2). Subgroup analysis comparing gastric emptying in NI to NN children and Thal to Nissen fundoplication did not show any significant differences.

\section{Predictors of LARS failure}

After LARS only one patient had persistent reflux symptoms and pathological reflux. As only one patient failed LARS, a logistic regression analysis was therefore not feasible.

\section{Predictors of the effect of LARS on reflux control}

Linear regression analysis identified preoperative reflux episodes on MII-pH monitoring as a determinant influencing the effect of LARS reflux episodes (estimate $=0.791 ; p<0.0001)$. Age at the time of operation, neurodevelopment, type of fundoplication and GE did not show any significant effect (Table 5). 


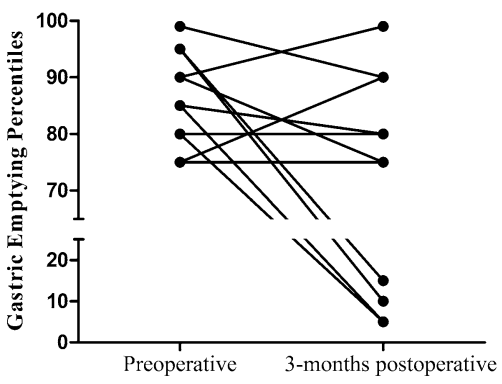

Fig. 2 Effect of LARS on gastric emptying in patients with preoperative delayed gastric emptying

\section{Discussion}

In the present study, LARS was successful in $96 \%$ of children with therapy-resistant GERD according to both the symptom and clinical response. LARS reduced not only acidic reflux episodes, but weakly acidic reflux was also significantly reduced.

Reflux symptoms significantly decreased after LARS, and in three $(12 \%)$ patients reflux symptoms persisted at 3 -month follow-up. This short-term success rate is similar to other prospective studies in pediatric antireflux surgery $[7,11,12]$. Subgroup analysis showed that the incidence of persistent or recurrent reflux symptoms was similar after both Thal and Nissen fundoplication $(p=0.597)$. A recent meta-analysis in both adults and children also reported no differences between partial and complete fundoplication techniques in reduction of reflux symptoms [34, 35]. It must be noted that our study was not powered to study the differences between both techniques and therefore results may differ in a larger study population.

When comparing reflux symptoms after LARS in children with NI to children with NN, we found that reflux symptoms were present in only $5 \%(1 / 20)$ of NN patients versus almost half $(40 \% ; 2 / 5)$ of NI children. This difference was not statistically different possibly because the current study was not powered to identify differences between both groups. Before LARS total acid exposure time and number of reflux episodes were significantly higher in NI children; however, after LARS no significant differences were observed. Some authors hypothesized that
NI children may insufficiently benefit from LARS [5, 36, 37]; however, we found no statistical significant differences in our study.

Only one of the three patients with persistent reflux symptoms also had pathological acid exposure on MII-pH monitoring; conversely, only one of the two (both NI) patients with pathological reflux had reflux symptoms after LARS. In the other NI patient, reflux symptoms completely resolved and 24-h MII-pH monitoring decreased to nearnormal acid exposure. In adults a lack of correlation between reflux symptoms and objective assessment of the prevalence of (acid) refluxate in the esophagus has been reported as well $[38,39]$. It is thought that recurrent or persistent symptoms may be caused by concomitant functional disease such as functional dyspepsia or hypersensitivity [39]. Moreover, in NI patients symptom assessment may be even more challenging because NI children are frequently verbally restricted and often have more (co-)morbidity, which underscores the importance of objective assessment of GERD in these children.

Objective assessment of reflux using 24-h MII-pH monitoring showed that LARS resulted in a significant decrease in acidic and also weakly acidic reflux. An earlier published pilot study by Loots et al. [8] did not show significant reduction in weakly acidic reflux. However, in this study only 10 patients were included, which may result in a type II error. Weakly acidic reflux is often not successfully treated by acid suppressive therapy (i.e., proton pump inhibitors) as it only decreases the acidity of the refluxate but does not treat the actual retrograde movement of gastric content [40]. Furthermore, in young children gastric content is buffered by frequent feeds and is therefore often not acidic.

LES resting and nadir pressure increased significantly after LARS, which is in accordance with previous studies on pediatric antireflux surgery $[12,36]$. Increase in the esophagogastric junction competence is expected, as it is one of the mechanisms in which LARS prevents GERD [41-43]. It has been reported that LARS may affect LES relaxations and esophageal motility, thereby inducing postoperative dysphagia [44]. In this current study, LARS did, however, not affect LES relaxations and esophageal motility.
Table 5 Predictors of the effect of LARS on reflux reduction

\begin{tabular}{lccl}
\hline & Estimate & $p$ value & $95 \%$ CI \\
\hline Age at time of operation & -6.1 & 0.76 & -47.2 to 34.9 \\
Neurodevelopment & 0.8 & 0.61 & -2.7 to 4.4 \\
Type of fundoplication & 3.4 & 0.85 & -33.8 to 40.6 \\
Preoperative total number of reflux episodes & 0.8 & $<0.0001$ & 0.5 to 1.1 \\
Preoperative gastric emptying & -0.2 & 0.34 & -0.6 to 0.2 \\
\hline
\end{tabular}

Linear regression analysis (95\% CI $95 \%$ confidence interval) 
In seven patients dysphagia was found after LARS. New-onset dysphagia was seen in three of these patients and was significantly more prevalent in NI children. Furthermore, a nonsignificant trend was shown in favor of Thal fundoplication (17 vs $57 \%$ ), compared to Nissen fundoplication. New-onset dysphagia is thought to be caused by fundoplication-induced restriction and postoperative swelling at the esophagogastric junction. LES pressure testing in our cohort did show a significant increase in LES resting and nadir pressure, which may reflect this restriction. Complete (e.g., Nissen) and partial (e.g., Thal and Toupet) fundoplications are all currently used in the pediatric population, and reported dysphagia rates differ between these techniques, but are mostly less prominent after partial fundoplication [7, 15, 35]. Finally, dysphagia may be a manifestation of GERD, as dysmotility of the distal esophagus is frequently seen in adult patients with esophagitis $[45,46]$.

In the current study, only one patient failed after LARS, which made a logistic regression analysis for the identification of predictors of LARS failure not possible. Rosen et al. also used MII-pH monitoring trying to identify predictors for LARS failure using a Cox regression analysis; however, their study was underpowered with only 37 patients and few failures and was not able to identify any predictors [19]. Despite the fact that logistic regression was not feasible, we still could perform a linear regression analysis that identified that the number of preoperative reflux episodes on MII-pH monitoring is a significant determinant influencing the effect of LARS. Patients with a higher number of reflux episodes on MII-pH monitoring had significantly more reflux reduction after LARS. Age at the time of operation, neurodevelopment and type of fundoplication did not show a significant effect. In the adult literature, preoperative delayed GE negatively influenced the success of LARS [45, 46]. In children with GERD, delayed GE may influence the severity of GERD [47, 48]. Therefore, for this study we hypothesized that preoperative delayed GE could be a risk factor for failure of LARS in our pediatric cohort. In linear regression analysis, GE was, however, not a significant predictor. LARS did significantly improve GE in patients with preoperative delayed or severely delayed GE, which has also been demonstrated in adults [47, 48] and children [49] that have undergone LARS.

One of the limitations of this current study was that we enrolled fewer patients than anticipated. Although most results on the efficacy of LARS showed statistically significant differences, the number of included patients limited our linear regression analysis and therefore we were only able to investigate five determinants assuming enough statistical power with five included patients per chosen predictor. As only one patient failed after LARS, a logistic regression analysis to identify predictors of failure was not possible. Furthermore, 3-month follow-up time may be too short. As published in the previous study [9], reflux symptoms may increase over time, and therefore, it is important that we closely follow-up this current group over the years.

In conclusion, LARS significantly reduces reflux complaints, total AET and number of (acidic) reflux episodes in children with therapy-resistant GERD. LES resting pressure increases significantly after LARS, but esophageal function was not affected by the procedure. GE significantly improved in patients with preoperative delayed gastric emptying, but in the overall group no differences were observed. LARS showed better reflux reduction in children with a higher number of reflux episodes on preoperative MII-pH monitoring. Identifying predictors for failure was not possible due to the low failure rate of LARS in this cohort at 3-month follow-up. Future studies should entail multicenter prospective trials with a higher number of patients and long-term follow-up to assess parameters in predicting success of therapy.

Acknowledgments F. A. Mauritz is supported by an unrestricted research grant of the Wilhelmina Children's Hospital Fund and Fund NutsOhra. No other sources of support were used.

\section{Compliance with ethical standards}

Disclosure All authors, F. A. Mauritz, J. M. Conchillo, L. W. E. van Heurn, P. D. Siersema, C. E. J. Sloots, R. H. J. Houwen, D. C. van der Zee and M. Y. A. van Herwaarden-Lindeboom, have no conflict of interest or any potential benefit in any form of a commercial party related directly or indirectly to the subject of the manuscript.

Open Access This article is distributed under the terms of the Creative Commons Attribution 4.0 International License (http://crea tivecommons.org/licenses/by/4.0/), which permits unrestricted use, distribution, and reproduction in any medium, provided you give appropriate credit to the original author(s) and the source, provide a link to the Creative Commons license, and indicate if changes were made.

\section{References}

1. Treem WR, Davis PM, Hyams JS (1991) Gastroesophageal reflux in the older child: presentation, response to treatment and longterm follow-up. Clin Pediatr (Phila) 30(7):435-440

2. Vandenplas Y, Rudolph CD, Di LC, Hassall E, Liptak G, Mazur L et al (2009) Pediatric gastroesophageal reflux clinical practice guidelines: joint recommendations of the North American Society for Pediatric Gastroenterology, Hepatology, and Nutrition (NASPGHAN) and the European Society for Pediatric Gastroenterology, Hepatology, and Nutrition (ESPGHAN). J Pediatr Gastroenterol Nutr 49(4):498-547

3. Sherman PM, Hassall E, Fagundes-Neto U, Gold BD, Kato S, Koletzko S et al (2009) A global, evidence-based consensus on the definition of gastroesophageal reflux disease in the pediatric population. Am J Gastroenterol 104(5):1278-1295 
4. Fonkalsrud EW, Ashcraft KW, Coran AG, Ellis DG, Grosfeld JL, Tunell WP et al (1998) Surgical treatment of gastroesophageal reflux in children: a combined hospital study of 7467 patients. Pediatrics 101(3 Pt 1):419-422

5. Capito C, Leclair MD, Piloquet H, Plattner V, Heloury Y, Podevin G (2008) Long-term outcome of laparoscopic NissenRossetti fundoplication for neurologically impaired and normal children. Surg Endosc 22(4):875-880

6. Engelmann C, Gritsa S, Gratz KF, Ure BM (2010) Laparoscopic anterior hemifundoplication improves key symptoms without impact on GE in children with and children without neurodevelopmental delays. J Pediatr Gastroenterol Nutr 51(4):437-442

7. Kubiak R, Andrews J, Grant HW (2011) Long-term outcome of laparoscopic nissen fundoplication compared with laparoscopic thal fundoplication in children: a prospective, randomized study. Ann Surg 253(1):44-49

8. Loots C, van Herwaarden MY, Benninga MA, VanderZee DC, van Wijk MP, Omari TI (2013) Gastroesophageal reflux, esophageal function, gastric emptying, and the relationship to dysphagia before and after antireflux surgery in children. J Pediatr 162(3):566-573

9. Mauritz FA, van Herwaarden-Lindeboom MY, Zwaveling S, Houwen RH, Siersema PD, van der Zee DC (2014) Laparoscopic Thal fundoplication in children: a prospective 10- to 15-year follow-up study. Ann Surg 259(2):388-393

10. van der Zee DC, Arends NJ, Bax NM (1999) The value of 24-h $\mathrm{pH}$ study in evaluating the results of laparoscopic antireflux surgery in children. Surg Endosc 13(9):918-921

11. Weber TR (1999) Toupet fundoplication for gastroesophageal reflux in childhood. Arch Surg 134(7):717-720

12. Soyer T, Karnak I, Tanyel FC, Senocak ME, Ciftci AO, Buyukpamukcu N (2007) The use of pH monitoring and esophageal manometry in the evaluation of results of surgical therapy for gastroesophageal reflux disease. Eur J Pediatr Surg 17(3):158-162

13. Esposito C, De Luca C, Alicchio F, Giurin I, Miele E, Staiano AM, Settimi A (2012) Long-term outcome of laparoscopic nissen procedure in pediatric patients with gastroesophageal reflux disease measured using the modified QPSG Roma III European Society for Pediatric Gastroenterology Hepatology and Nutrition's Questionnaire. J Laparoendosc Adv Surg Tech A 22(9):937-940

14. Kimber C, Kiely EM, Spitz L (1998) The failure rate of surgery for gastro-oesophageal reflux. J Pediatr Surg 33(1):64-66

15. Mauritz FA, van Herwaarden-Lindeboom MY, Stomp W, Zwaveling S, Fischer K, Houwen RH et al (2011) The effects and efficacy of antireflux surgery in children with gastroesophageal reflux disease: a systematic review. J Gastrointest Surg 15(10): 1872-1878

16. Draaisma WA, Rijnhart-de Jong HG, Broeders IA, Smout AJ, Furnee EJ, Gooszen HG (2006) Five-year subjective and objective results of laparoscopic and conventional Nissen fundoplication: a randomized trial. Ann Surg 244(1):34-41

17. Sifrim D, Castell D, Dent J, Kahrilas PJ (2004) Gastro-oesophageal reflux monitoring: review and consensus report on detection and definitions of acid, non-acid, and gas reflux. Gut 53(7):1024-1031

18. Loots CM, Benninga MA, Davidson GP, Omari TI (2009) Addition of $\mathrm{pH}$-impedance monitoring to standard $\mathrm{pH}$ monitoring increases the yield of symptom association analysis in infants and children with gastroesophageal reflux. J Pediatr 154(2):248-252

19. Rosen R, Levine P, Lewis J, Mitchell P, Nurko S (2010) Reflux events detected by $\mathrm{pH}-\mathrm{MII}$ do not determine fundoplication outcome. J Pediatr Gastroenterol Nutr 50(3):251-255

20. Fukahori S, Asagiri K, Ishii S, Tanaka Y, Kojima S, Saikusa N et al (2013) Pre and post-operative evaluation of gastroesophageal reflux and esophageal motility in neurologically impaired children using combined $\mathrm{pH}$-multichannel intraluminal impedance measurements. Pediatr Surg Int 29(6):545-551

21. Humphries LA, Hernandez JM, Clark W, Luberice K, Ross SB, Rosemurgy AS (2013) Causes of dissatisfaction after laparoscopic fundoplication: the impact of new symptoms, recurrent symptoms, and the patient experience. Surg Endosc 27(5):1537-1545

22. Thal AP (1968) A unified approach to surgical problems of the esophagogastric junction. Ann Surg 168:542

23. Nissen R (1956) Eine einfache operation zur beeinflussung der refluxoesophagitis. Schweiz Med Wochenschr 86(Suppl 20):590-592

24. Deal L, Gold BD, Gremse DA, Winter HS, Peters SB, Fraga PD et al (2005) Age-specific questionnaires distinguish GERD symptom frequency and severity in infants and young children: development and initial validation. J Pediatr Gastroenterol Nutr 41(2): $178-185$

25. TNO Groeicalculator voor de vijfde landelijke Groeistudie. 2013. https://groeiweb.pgdata.nl/calculator.asp

26. Pandolfino JE, Kahrilas PJ (2005) AGA technical review on the clinical use of esophageal manometry. Gastroenterology 128(1):209-224

27. Richter JE, Bradley LA, DeMeester TR, Wu WC (1992) Normal 24-hr ambulatory esophageal $\mathrm{pH}$ values. Influence of study center, pH electrode, age, and gender. Dig Dis Sci 37(6):849-856

28. Smout AJ, Breedijk M, van der Zouw C, Akkermans LM (1989) Physiological gastroesophageal reflux and esophageal motor activity studied with a new system for 24-hour recording and automated analysis. Dig Dis Sci 34(3):372-378

29. Omari TI, Schwarzer A, vanWijk MP, Benninga MA, McCall L, Kritas $S$ et al (2011) Optimisation of the reflux-symptom association statistics for use in infants being investigated by 24-hour pH impedance. J Pediatr Gastroenterol Nutr 52(4):408-413

30. Weusten BL, Roelofs JM, Akkermans LM, Van Berge-Henegouwen GP, Smout AJ (1994) The symptom-association probability: an improved method for symptom analysis of 24-hour esophageal $\mathrm{pH}$ data. Gastroenterology 107(6):1741-1745

31. Ghoos YF, Maes BD, Geypens BJ, Mys G, Hiele MI, Rutgeerts PJ et al (1993) Measurement of gastric emptying rate of solids by means of a carbon-labeled octanoic acid breath test. Gastroenterology 104(6):1640-1647

32. van den Driessche M, Ghoos Y, Veereman-Wauters G. Maturation of gastric emptying in healthy infants and children and reference values for the ${ }^{13} \mathrm{C}$ octanoic acid breath test. Chapter as part of the dissertation of M. van den Driessche, University of Leuven

33. Harrell FE Jr, Lee KL, Califf RM, Pryor DB, Rosati RA (1984) Regression modelling strategies for improved prognostic prediction. Stat Med 3(2):143-152

34. Broeders JA, Mauritz FA, Ahmed AU, Draaisma WA, Ruurda JP, Gooszen HG et al (2010) Systematic review and meta-analysis of laparoscopic Nissen (posterior total) versus Toupet (posterior partial) fundoplication for gastro-oesophageal reflux disease. Br J Surg 97(9):1318-1330

35. Mauritz FA, Blomberg BA, Stellato RK, van der Zee DC, Siersema PD, van Herwaarden-Lindeboom MY (2013) Complete versus partial fundoplication in children with gastroesophageal reflux disease: results of a systematic review and meta-analysis. J Gastrointest Surg 17(10):1883-1892

36. Kawahara H, Okuyama H, Kubota A, Oue T, Tazuke Y, Yagi M et al (2004) Can laparoscopic antireflux surgery improve the quality of life in children with neurologic and neuromuscular handicaps? J Pediatr Surg 39(12):1761-1764

37. Lobe TE (2007) The current role of laparoscopic surgery for gastroesophageal reflux disease in infants and children. Surg Endosc 21(2):167-174 
38. Broeders JA, Rijnhart-de Jong HG, Draaisma WA, Bredenoord AJ, Smout AJ, Gooszen HG (2009) Ten-year outcome of laparoscopic and conventional nissen fundoplication: randomized clinical trial. Ann Surg 250(5):698-706

39. Kessing BF, Bredenoord AJ, Schijven MP, van der Peet DL, van Berge Henegouwen MI, Smout AJ (2015) Long-term effects of anti-reflux surgery on the physiology of the esophagogastric junction. Surg Endosc 29(12):3726-3732

40. Loots CM, Wijnakker R, van Wijk MP, Davidson G, Benninga MA, Omari TI (2012) Esophageal impedance baselines in infants before and after placebo and proton pump inhibitor therapy. Neurogastroenterol Motil 24(8):758-e352

41. Dent J, Holloway RH, Toouli J, Dodds WJ (1988) Mechanisms of lower oesophageal sphincter incompetence in patients with symptomatic gastrooesophageal reflux. Gut 29(8):1020-1028

42. Ireland AC, Holloway RH, Toouli J, Dent J (1993) Mechanisms underlying the antireflux action of fundoplication. Gut 34(3):303-308

43. Scheffer RC, Tatum RP, Shi G, Akkermans LM, Joehl RJ, Kahrilas PJ (2003) Reduced tLESR elicitation in response to gastric distension in fundoplication patients. Am J Physiol Gastrointest Liver Physiol 284(5):G815-G820

44. Kawahara H, Dent J, Davidson G (1997) Mechanisms responsible for gastroesophageal reflux in children. Gastroenterology 113(2):399-408

45. Diener U, Patti MG, Molena D, Fisichella PM, Way LW (2001) Esophageal dysmotility and gastroesophageal reflux disease. J Gastrointest Surg 5(3):260-265

46. Weber TR (1995) A prospective analysis of factors influencing outcome after fundoplication. J Pediatr Surg 30(7):1061-1063

47. Maddern GJ, Jamieson GG (1985) Fundoplication enhances gastric emptying. Ann Surg 201(3):296-299

48. Vu MK, Straathof JW, Schaar PJ, Arndt JW, Ringers J, Lamers $\mathrm{CB}$ et al (1999) Motor and sensory function of the proximal stomach in reflux disease and after laparoscopic Nissen fundoplication. Am J Gastroenterol 94(6):1481-1489

49. Estevao-Costa J, Fragoso AC, Prata MJ, Campos M, Trindade E, Dias JA et al (2011) Gastric emptying and antireflux surgery. Pediatr Surg Int 27(4):367-371 